\title{
Modifications of Heat Transfer and Induced Flow Rate of a Solar Chimney by an Obstacle in the Air Channel
}

\author{
Y Quoc Nguyen ${ }^{\mathrm{a}, *}$, Trieu Nhat Huynh ${ }^{\mathrm{a}}$, Mai-Anh Ho Pham ${ }^{\mathrm{b}}$ \\ ${ }^{a}$ Faculty of Engineering, Van Lang University, 45 Nguyen Khac Nhu St., Ho Chi Minh City, 70000, Vietnam \\ ${ }^{b}$ Faculty of Garment Technology and Fashion, Ho Chi Minh City University of Food Industry, Ho Chi Minh City, 70000, Vietnam \\ Corresponding author: ${ }^{*}$.nq@vlu.edu.vn
}

\begin{abstract}
Using renewable energy resources in buildings has been increasing for saving energy. Among widely used methods, solar chimneys absorb solar radiation and induce an airflow for ventilation, heating, or cooling buildings. The performance of a solar chimney depends on the heat transfer in its air channel, which can be modified by changing the shape of the heat exchange surface. In this study, we examine the effects of a rectangular obstacle placed on the heated surface of the air channel of a solar chimney. A numerical model was built with the Computational Fluid Dynamics (CFD) technique. By changing the geometries of the chimney and of the obstacle, and location of the obstacle, it was found that the obstacle had strong effects on the local flow and heat transfer properties close to the object, particularly the Nusselt number and the temperature field. However, average quantities of the whole air channel flow, such as the averaged Nusselt number and the induced flow rate, were modified insignificantly, except for the temperature rise through the chimney and the thermal efficiency. The change of the flow rate and the average Nusselt number was $5.0 \%$ while the temperature rises and the thermal efficiency was up to $13.0 \%$. The height of the obstacle had more influence than the length. This study suggests more investigations to achieve the objective of enhancing the induced flow rate for ventilation of buildings with an obstacle in the air channel of a solar chimney.
\end{abstract}

Keywords - Renewable energy; solar chimney; buildings; ventilation; nusselt number; CFD

Manuscript received 26 Jul. 2020; revised 31 Jan. 2021; accepted 28 Feb. 2021. Date of publication 30 Apr. 2021. IJASEIT is licensed under a Creative Commons Attribution-Share Alike 4.0 International License.

\section{INTRODUCTION}

Renewable energy resources have been employed in buildings with many methods [1], and among them, solar radiation has been harnessed for natural ventilation with solar chimneys [2]-[5]. A typical solar chimney consists of an air channel enclosed by a transparent cover and an absorber surface, such as a building wall [6]-[10]. Once exposed to solar radiation, the transparent cover allows the radiation to pass through and absorb the absorber surface. The air in the channel receives heat from the absorber surface and is warmed up. With thermal effects due to the air temperature rise and the elevation difference between the inlet and the air channel outlet, an airflow is induced and used for ventilating the building or cooling its facades [1], [2].

A solar chimney's exposed wall can also absorb solar radiation directly [2], [11]. The absorbed heat is conducted through the cover plate and transferred to the air in the channel. When integrated into a building, solar chimneys can have different forms, including Trombe wall [12], roof-top solar chimney [13], or combined wall and roof solar chimney [14]. Many factors influence the ventilation performance of a solar chimney [3], [15]-[17]. Major ones include geometries of the air channel and the wall, such as the height and the gap of the air channel; material of the walls of the air channel; and weather conditions, such as solar radiation [3], [15]-[17].

Modifications of the air channels' shapes have been tested to improve a solar chimney's performance [18]-[20]. Khanal and Lei [18] proposed a solar chimney with an inclined transparent cover for enhancing the induced flow rate by suppressing the flow reversal at the chimney's outlet. AlKayiem et al. [19] reported that the highest flow rate through a solar roof chimney was achieved when the glazing plate was longer than the absorber surface. A similar achievement was also obtained with a bell-shaped inlet of the air channel by Singh et al. [20].

Attempts have also been focused on enhancing the heat transfer between the absorber surface and the air in the 
chimney channel by changing the absorber surface's shape [13], [18]. Lei et al. [13] employed a perforated absorber plate for a roof solar chimney, while Pangavhane et al. [21] tested a corrugated one. Chorin et al. [22] measured heat transfer rate in a closed cavity heated on one wall and an obstacle on the heated wall. Their results show that the heat transfer rate increased around the obstacle. The velocity distribution of the flow around the obstacle was also significantly modified. However, because of the cavity in their experiment was closed, no induced flow rate through the cavity was reported. Therefore, the effects of a single obstacle on the heated wall of the air channel of a solar chimney are still questioned. In this study, we focused on the effects of an obstacle on a solar chimney's absorber surface whose cover surface absorbs solar radiation directly. A CFD model examined modifications of the heat transfer obstacle, induced flow rate, temperature rise, and thermal efficiency.

\section{Material AND Method}

\section{A. Descriptions of the Problem}

The studied solar chimney, as sketched in Fig. 1a, was attached to a vertical wall of a building. It consisted of an absorber plate, such as a metal sheet, placed close to the wall. The air channel gap between the plate and the wall was denoted as $\mathrm{G}$, while the chimney's height was $\mathrm{H}$. It was assumed that the chimney's third dimension was much larger than $\mathrm{G}$, and the chimney was considered in two dimensions as in Fig. 1a.

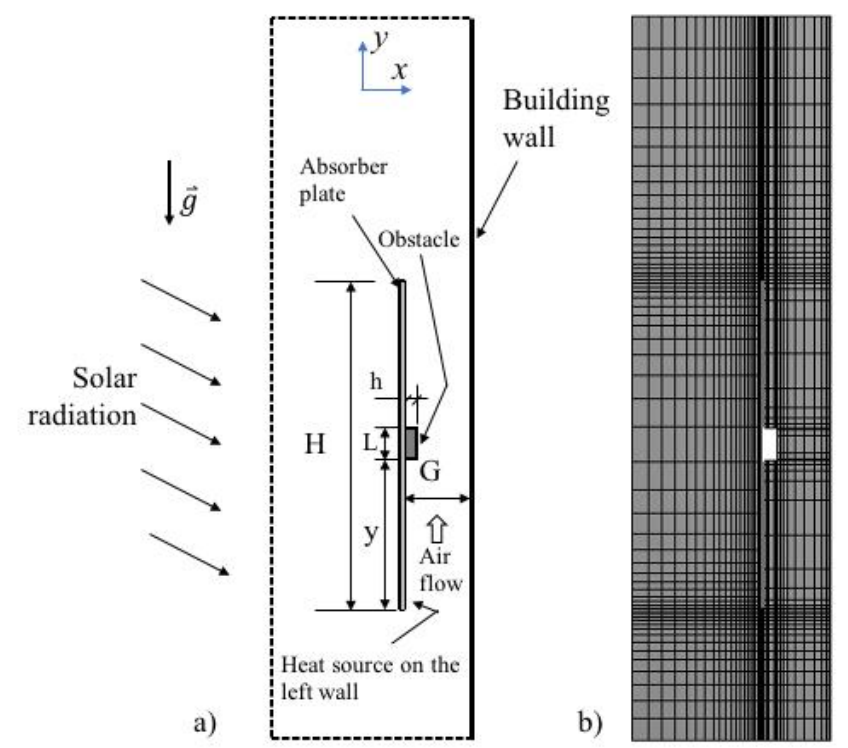

Fig. 1 The schematic of the studied solar chimney (a) and the computational domain and mesh (b).

Solar radiation was absorbed by the absorber plate and conducted through the plate thickness into its inner surface. Inside the air channel, the absorbed heat was then transferred to the air mostly through convection. Warmed air might rise in the air channel due to the stack (thermal) effects. The induced airflow can be used for ventilation on the building or cooling the building facades [23].

A rectangular obstacle $(\mathrm{OB})$ was placed on the surface of the air channel's heated surface (Fig. 1a). Its length and height were denoted as $\mathrm{L}$ and $\mathrm{h}$, respectively. $\mathrm{y}$ was the distance of the obstacle from the inlet of the air channel.

\section{B. Numerical Method}

A computational model based on the Computational Fluid Dynamics (CFD) technique was built to predict the airflow and heat transfer in the chimney's air channel. The governing equations described the continuity (mass), momentum, and energy conservation principles. They were described by the Reynolds Averaged Navier - Stokes (RANS) equations, with the following assumptions:

- The airflow and heat transfer are steady and two dimensional.

- The airflow is incompressible.

- The fluid properties follow the Bossiness approximation.

- Effects of radiation heat transfer between two surfaces of the air channel are negligible.

- Heat loss through the thickness of the absorber plate is not modeled.

A turbulence model is also required for simulation as the airflow in typical solar chimneys is turbulent [23]. The two dimensional forms of the governing equations in forms of tensor notation are as follows [23]-[25].

$$
\begin{gathered}
\frac{\partial u_{j}}{\partial x_{j}}=0 \\
\frac{\partial\left(u_{i} u_{j}\right)}{\partial x_{j}}=-\frac{1}{\rho} \frac{\partial p}{\partial x_{i}}-g_{i} \beta\left(T-T_{r e f}\right)+\frac{\partial}{\partial x_{j}}\left(v \frac{\partial u_{i}}{\partial x_{j}}-\overline{u_{i}^{\prime} u_{j}^{\prime}}\right) \\
\frac{\partial\left(T u_{j}\right)}{\partial x_{j}}=\frac{\partial}{\partial x_{j}}\left(\frac{v}{\operatorname{Pr}} \frac{\partial T}{\partial x_{j}}-\overline{T^{\prime} u_{j}^{\prime}}\right)
\end{gathered}
$$

where $\mathbf{u}, \mathrm{p}$, and $\mathrm{T}$ denote the velocity, temperature, and pressure, respectively; $\rho, v$, and $\operatorname{Pr}$ stand for the air density, kinematic viscosity, and the Prandtl number, respectively; $\beta$ is the thermal expansion coefficient of the air; ' indicates the fluctuating component; - presents a time-averaged quantity.

The reference temperature $T_{\text {ref }}$ was taken as the ambient one.

In this study, the RNG k- $\varepsilon$ model [26] was employed for the turbulent stress $\overline{u_{i}^{\prime} u_{j}^{\prime}}$ and the turbulent heat flux $\overline{T^{\prime} u_{j}^{\prime}}$. It was selected as it offered the most stable and fastest convergence speed among the available turbulence models, such as the standard $k-\varepsilon$ or the standard $k-\omega[23]-[25]$.

The governing equations were discretized with the Finite Volume Method on a structured rectangular grid, shown in Fig. 1b. The computational domain consisted of both the air channel and ambient air, as suggested by Gan [27]. The mesh was clustered near the solid surface, particularly near the heated and the obstacle surfaces.

For the flow boundary conditions, the building wall and the absorber plate's surfaces, and the obstacle were treated with no-slip conditions. Other open boundaries of the domain were set to atmospheric pressure. Uniform heat flux was applied on the heated surface. Other solid surfaces were considered as adiabatic walls.

The commercial CFD code ANSYS Fluent Academic Version 2019R3 was employed for the numerical setup, with the SIMPLE scheme for the coupling between the continuity and momentum equations. The mesh density was also 
checked carefully to achieve mesh - independence solutions. Details about the numerical setup can be found in $[25,26]$.

For validation, the computational model was tested with the experiment by Burek and Habeb [12]. Their experiments were conducted with a vertical solar chimney with $\mathrm{H}=1.025$ $\mathrm{m}$. The gap changed from $20 \mathrm{~mm}$ to $110 \mathrm{~mm}$, and the width of the chimney was $0.92 \mathrm{~m}$. The induced flow rate through the air channel was measured at different heat fluxes.

Fig. 2 shows the comparison of the measured and computed flow rate at two total heat inputs of $1000 \mathrm{~W}$ and $600 \mathrm{~W}$. The computed data could match the measured ones well with the maximum discrepancy of less than $8.0 \%$.

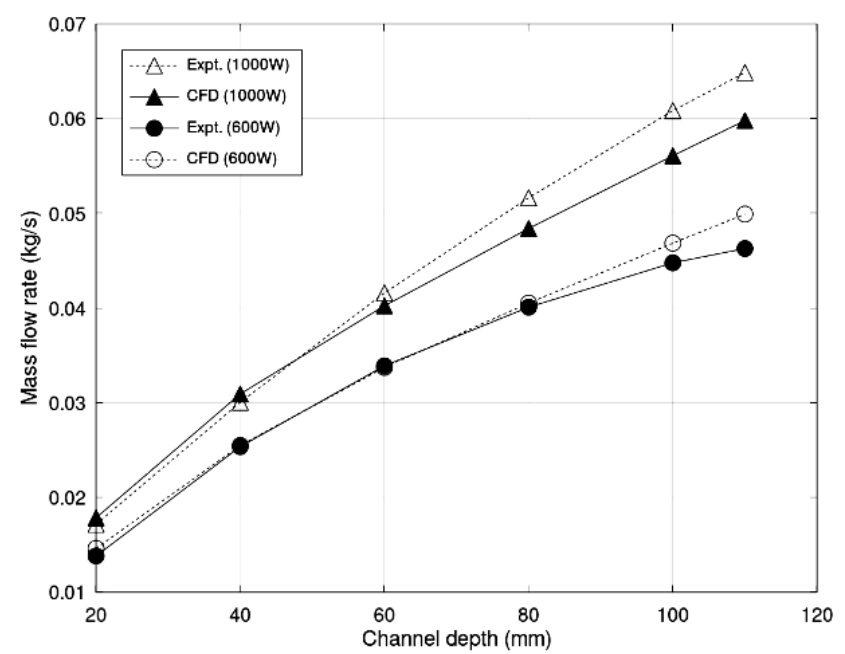

Fig. 2 Induced flow rate through the solar chimney in the experiment by Burek and Habeb [12]: Numerical vs Experimental data

\section{RESULTS AND DisCUSSIONS}

In this section, the effects of the obstacle were examined in terms of the flow field, Nusselt number, induced flow rate, temperature rise, and thermal efficiency of the airflow through the chimney. The tested chimney height was fixed to $\mathrm{H}=1.0 \mathrm{~m}$ while $\mathrm{G}, \mathrm{h}, \mathrm{L}$ changed to result in the ratio $\mathrm{G} / \mathrm{H}=0.1$ and $0.2 ; \mathrm{h} / \mathrm{G}=0.1$ and 0.2 ; and $\mathrm{L} / \mathrm{H}=0.05$ and 0.1 . The location of the obstacle in the air channel also varied. The heat flux on the heated surface was kept to $400 \mathrm{~W} / \mathrm{m}^{2}$.

\section{A. Flow and Temperature Fields}

The flow and temperature fields of the solar chimney with and without the obstacle are presented in Fig. 3. The obstacle was placed at $\mathrm{y} / \mathrm{H}=0.3$ and 0.6 . The thermal layer near the heated surface developed continuously from the air channel's inlet without the obstacle. With the obstacle, the thermal layer was disturbed around the object. The disturbed region was larger at $\mathrm{y} / \mathrm{H}=0.6$. However, at the outlet, the temperature distributions were slightly different from each other. Similar effects were also seen for the flow field. As passing the obstacle, where the flow area was contracted, the velocity increased. However, further downstream of the objects, the velocity distributions quickly recovered to the cases without the obstacle.

\section{B. Distributions of the Nusselt Number}

Fig. 4 shows the distributions of the local Nusselt number on the cases' heated wall in Fig. 3. The Nusselt number is defined as in (4).

$$
N u=\frac{q_{w} G}{\left(T_{w}-T_{a}\right) \lambda}
$$

where $q_{w}$ and $T_{w}$ are the heat flux and temperature of the wall, respectively; $T_{a}$ is the air temperature at the inlet of the air channel; and $\lambda$ is the air thermal conductivity.

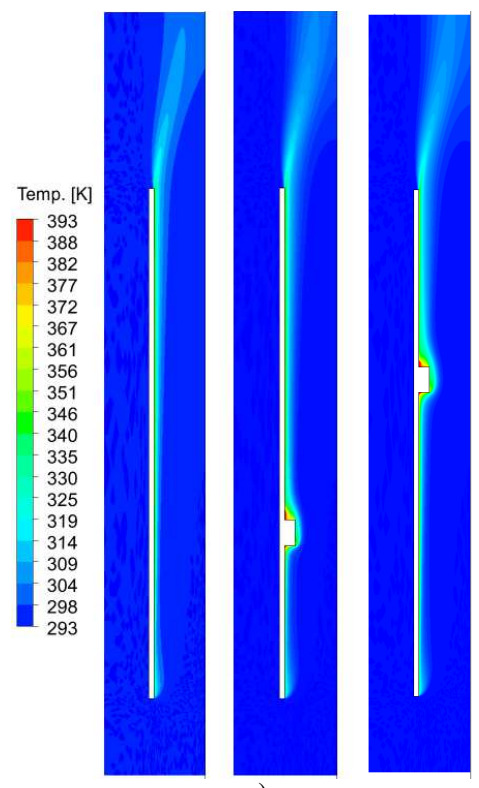

a)

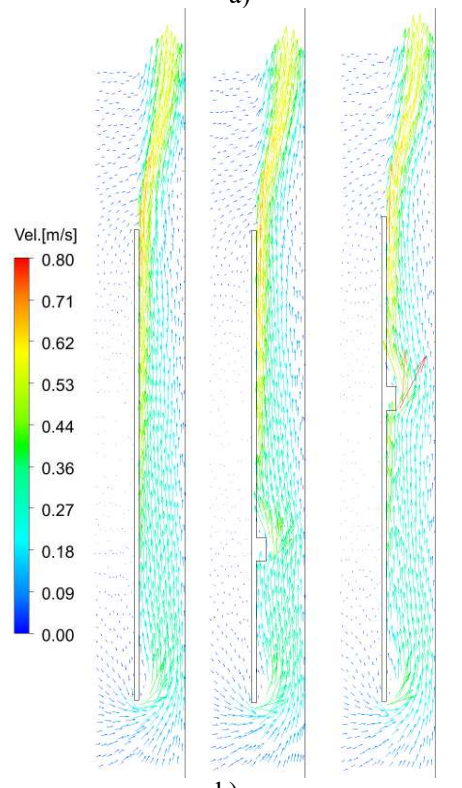

b)

Fig. 3 Temperature distributions (a) and velocity vectors (b) through the solar chimney $(\mathrm{H}=1.0 \mathrm{~m}, \mathrm{G}=0.1 \mathrm{~m})$ without and with the obstacle $(\mathrm{h}=0.02 \mathrm{~m})$ at $\mathrm{y} / \mathrm{H}=0.3$ and 0.6

It is seen in Fig. 4 that the Nusselt number was strongly modified around the obstacle. In both cases of $\mathrm{y} / \mathrm{H}$, close to $\mathrm{OB}$, the Nusselt number dropped at both before and after OB. Further downstream, the $\mathrm{Nu}$ increased then went back to the base case (without the obstacle). The increase of $\mathrm{Nu}$ compared to that of the base case was higher for $\mathrm{y} / \mathrm{H}=0.6$. A similar increase of the Nu after the $\mathrm{OB}$ was also reported by Chorin et al. [22]. However, they did not report the decrease of $\mathrm{Nu}$ close to the OB. It is possible because their 
measurement points were not sufficiently close to the OB to capture that trend.

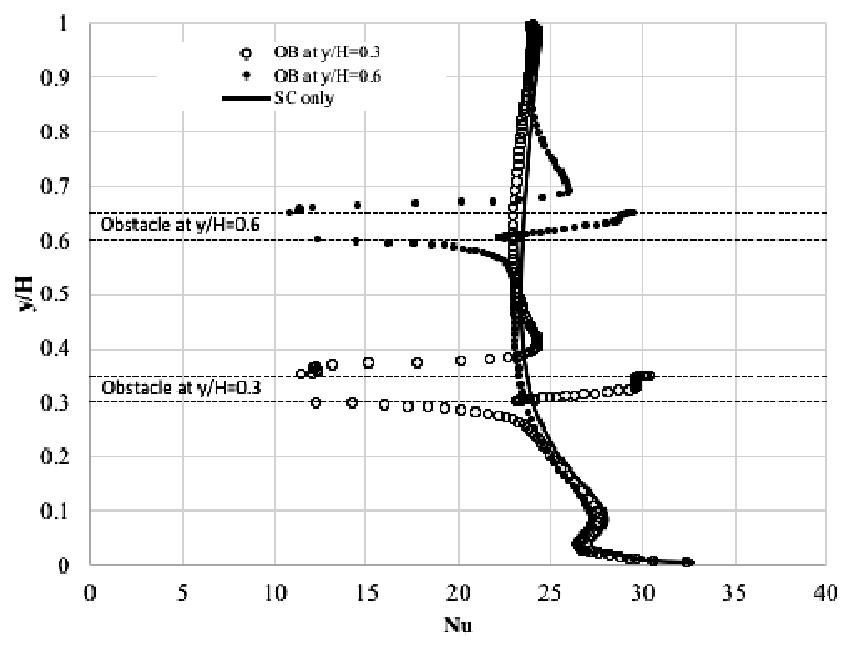

Fig. 4 Distributions of Nusselt number along the heated surface of the solar chimney $(\mathrm{H}=1.0 \mathrm{~m}, \mathrm{G}=0.1 \mathrm{~m})$ without and with the obstacle $(\mathrm{h}=0.02$ $\mathrm{m})$ at $\mathrm{y} / \mathrm{H}=0.3$ and 0.6

According to (4), the local Nusselt number depends on both $q_{w}$ and $T_{w}$. As $q_{w}$ and $T_{a}$ were fixed to $400 \mathrm{~W} / \mathrm{m}^{2}$ on the whole surface of the heated wall and $293.15 \mathrm{~K}$, respectively, the Nusselt number was proportional to $1 / T_{w}$. As seen in Fig. 3, there were two separation zones right before and after $\mathrm{OB}$. Inside these zones, the air temperatures were much higher than that of the base case's thermal layer at the same locations. This result may explain the reduction of the Nusselt number in those regions. Further downstream of the rear separation zone, the flow was re-attached with higher velocity, hence lower wall temperature and increase of the Nusselt number.

\section{Averaged Nusselt number}

The Nusselt number was averaged on the whole heated surface by (5).

$$
N u_{a v}=\frac{\int_{0}^{H} N u d l}{H}
$$

The averaged Nusselt number is plotted in Fig. 5 for different values of $\mathrm{G}, \mathrm{h}, \mathrm{L}$, and $\mathrm{y} . N u_{a v}$ was normalized by the averaged value of the base case, $N u_{\text {base }}$.

In general, the ratio of $N u_{a v} / N u_{\text {base }}$ increased with the distance $\mathrm{y} / \mathrm{H}$ of $\mathrm{OB}$. However, the change was minor and within $5 \%$. The ratio was essentially less than 1.0 . Therefore, the presence of $\mathrm{OB}$ reduced the averaged Nusselt number on the heated surface. In Fig. 5a, the data trends were similar for different L's but different for different h's. Similar trends can also be seen in Fig. 5b. Therefore, between the two dimensions of $\mathrm{OB}$, it is expected that $\mathrm{h}$ had more influence on $N u_{a v}$ than L. It is also observed in Fig. 5 that increasing $\mathrm{h}$ shifted the data lines down; hence reduced the averaged Nusselt number compared to that of the base case.

\section{Induced flow rate}

The induced mass flow rate $Q$ through the chimneys in Fig. 5 was plotted in Fig. 6 and normalized by the base case $Q_{\text {base }}$. It is seen that the flow rate slightly increased compared to the base case when $\mathrm{OB}$ is on the lower half of the heated wall. As the location of $\mathrm{OB}$ moved up, the flow rate decreased. However, the change in the flow rate was only within $\pm 4.0 \%$. This number agrees with the observations in Fig. 3 and the data in Fig. 5, which indicate that $\mathrm{OB}$ had negligible effects on the averaged Nusselt number and the whole air channel's flow field.

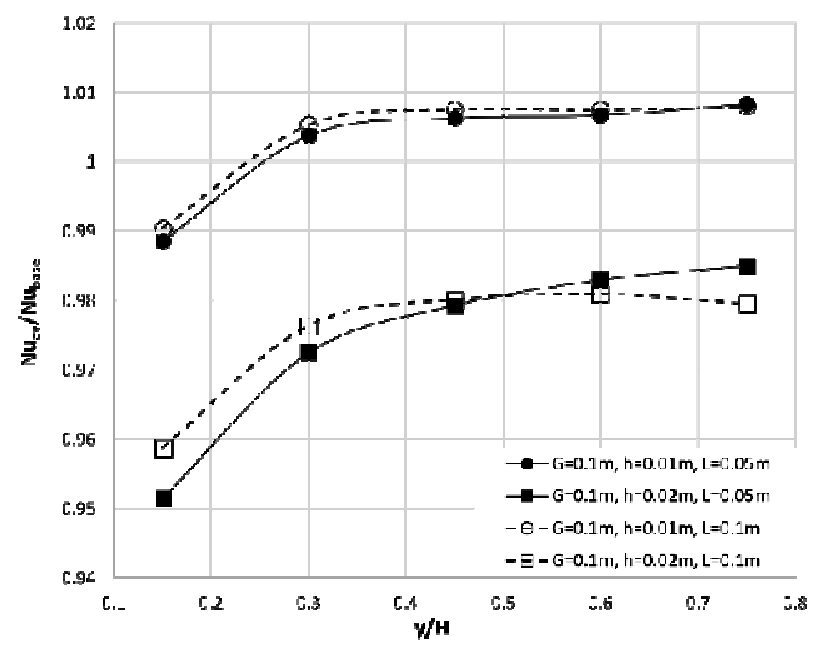

(a)

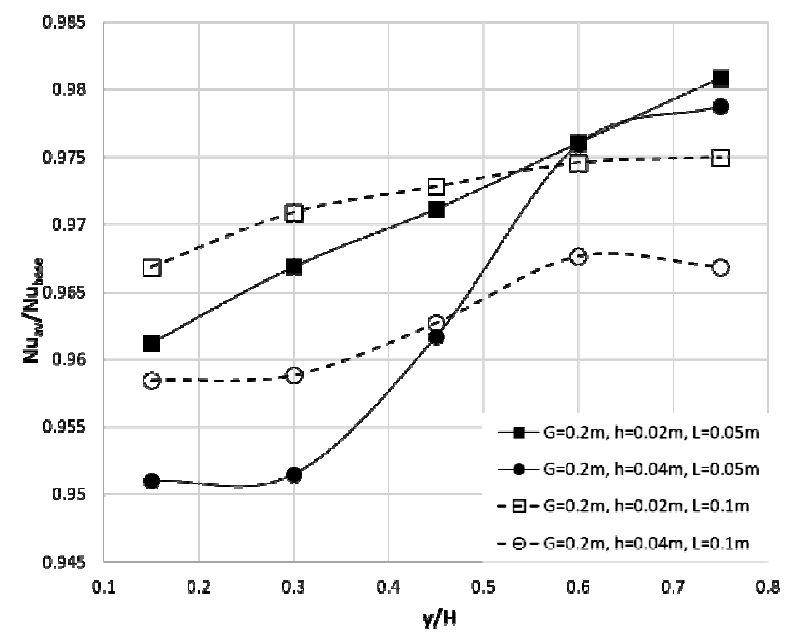

(b)

Fig. 5 Plots of the averaged Nusselt number for $G=0.1 \mathrm{~m}$ (a) and $\mathrm{G}=0.2 \mathrm{~m}$ (b) at different values of $\mathrm{h}, \mathrm{L}$, and $\mathrm{y}$

\section{E. Temperature rise}

The temperature rise of the airflow through the channel is defined as the temperature difference between the outlet and the inlet by (6).

$$
\Delta T=T_{o}-T_{i}
$$

where $T_{o}$ and $T_{i}$ are the air temperatures at the outlet and the inlet of the air channel, respectively. 


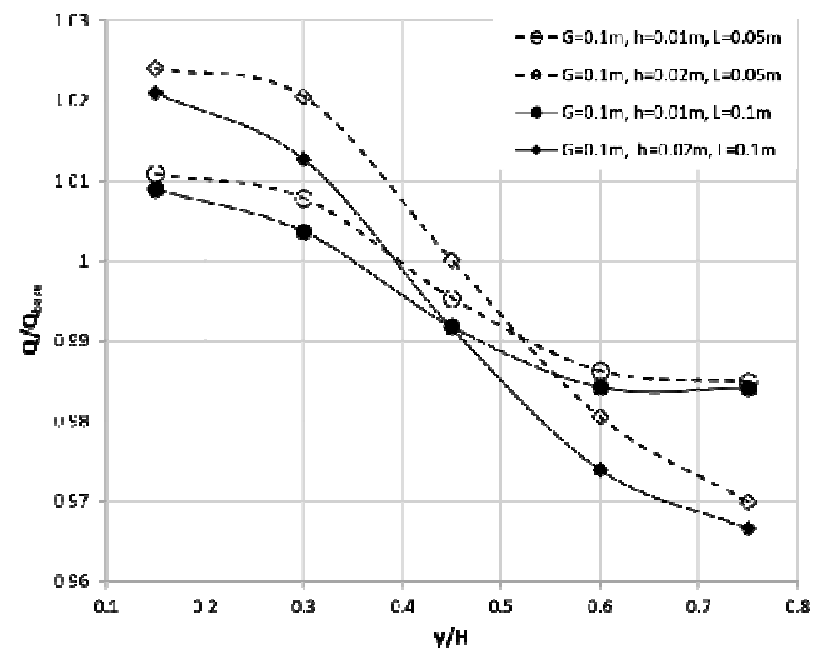

(a)

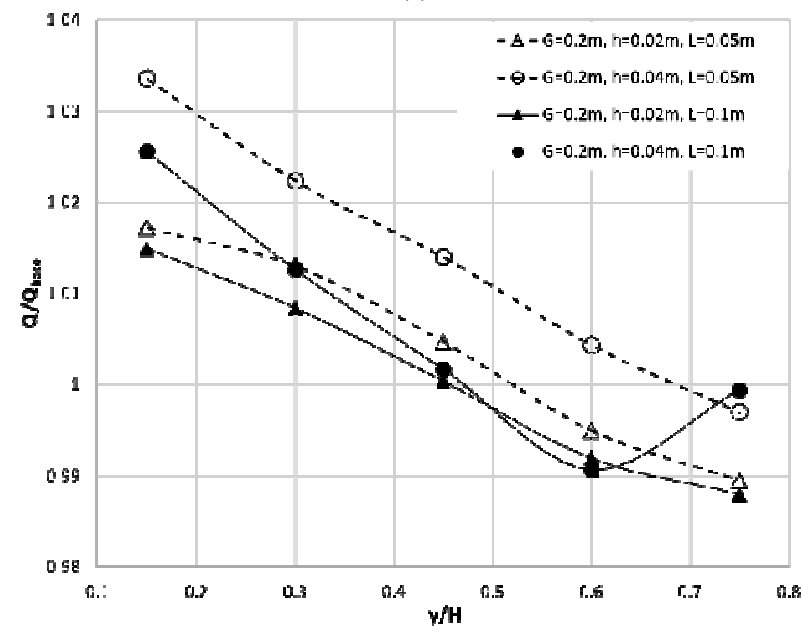

(b)

Fig. 6 Plots of the ratio of the induced flow rate $Q / Q_{\text {base }}$ for $\mathrm{G}=0.1 \mathrm{~m}$ (a) and $\mathrm{G}=0.2 \mathrm{~m}$ (b) at different values of $\mathrm{h}, \mathrm{L}$, and $\mathrm{y}$

Fig. 7 displays the temperature rise $\Delta \mathrm{T}$, which is normalized by that of the base case $\Delta \mathrm{T}_{\text {base. In all cases, }}$ $\Delta T / \Delta T_{\text {base }}$ is larger than 1.0. Therefore, the presence of $\mathrm{OB}$ increased the temperature rise through the air channel. The maximum increase was about $6.0 \%$ for $\mathrm{G}=0.1 \mathrm{~m}$, but up to about $13.0 \%$ for $\mathrm{G}=0.2 \mathrm{~m}$.

It is observed in Fig. 7 that $\Delta T / \Delta T_{\text {base }}$ increased with both $\mathrm{L}$ and $\mathrm{h}$. However, the effects of $\mathrm{h}$ are more significant than that of $\mathrm{L}$. The increase of $\Delta T / \Delta T_{\text {base }}$ due to $\mathrm{L}$ was less than $1.0 \%$ for both $\mathrm{G}$ values while that $\mathrm{h}$ was $4.0 \%$ for $\mathrm{G}=0.1 \mathrm{~m}$ and $8.0 \%$ for $\mathrm{G}=0.2 \mathrm{~m}$.

As $\mathrm{y} / \mathrm{H}$ increased, particularly when $\mathrm{y} / \mathrm{H}>0.6$ in Fig. $7 b$, $\Delta \mathrm{T}$ was strongly enhanced. This trend can be seen in Fig. 3. The thermal boundary layer was enlarged around OB. As OB was closer to the air channel outlet, the outlet's thermal boundary became thicker and yielded higher average air temperature $\mathrm{T}_{\mathrm{o}}$; hence higher $\Delta \mathrm{T}$.

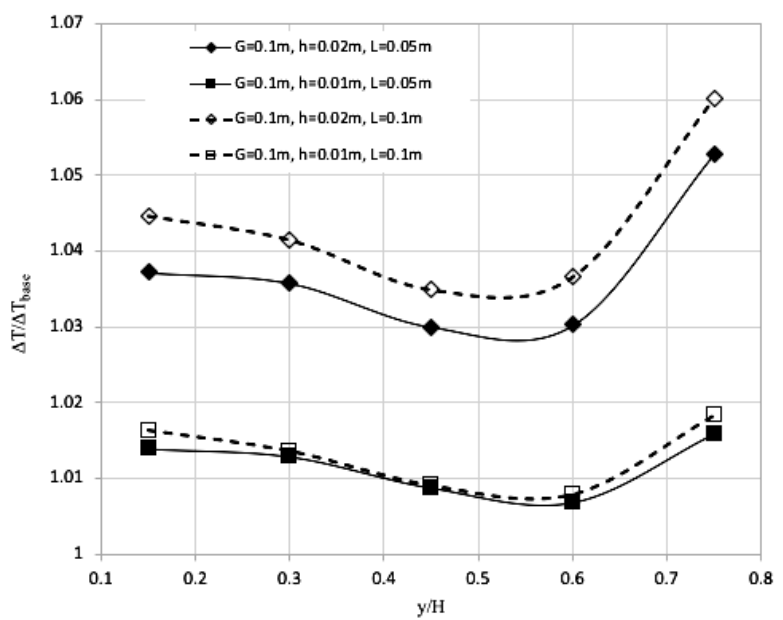

(a)

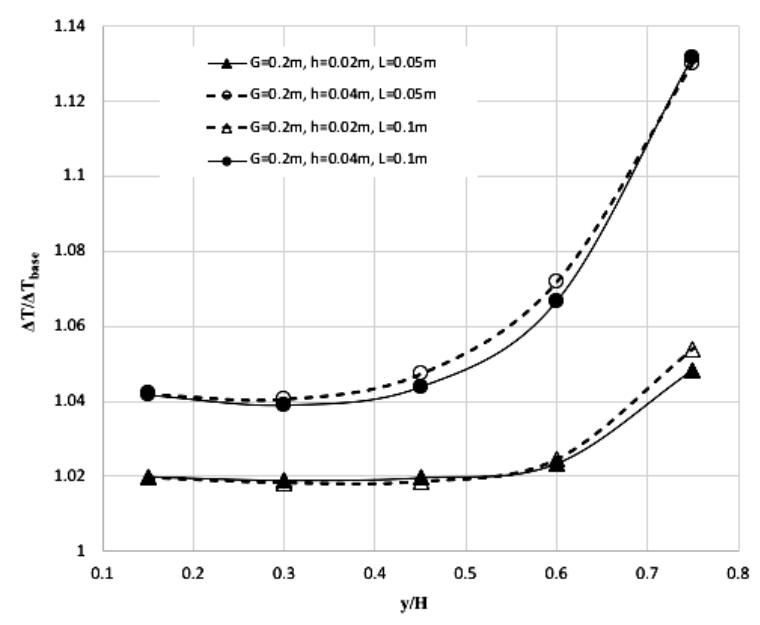

(b)

Fig. 7 Plots of the ratio of the temperature rise $\Delta T / \Delta T_{\text {base }}$ for $\mathrm{G}=0.1 \mathrm{~m}$ (a) and $\mathrm{G}=0.2 \mathrm{~m}$ (b) at different values of $\mathrm{h}, \mathrm{L}$, and $\mathrm{y}$

\section{F. Thermal efficiency}

The thermal efficiency of the solar chimney was calculated by (7) $[12,21,22]$.

$$
\eta=\frac{I_{0}}{I_{i}}=\frac{Q c_{p} \Delta T}{I_{i}}=\frac{Q c_{p}\left(T_{o}-T_{i}\right)}{I_{i}}
$$

$\mathrm{Q}$ is the mass flow rate; $\square$ is the specific heat capacity of air, and $\square$ is the air channel's heat input.

The thermal efficiency normalized by that of the base cases, $\eta / \eta_{\text {base }}$, is presented in Fig. 8 . For $\mathrm{G}=0.1$, the presence of OB reduced the thermal efficiency up to about $6.0 \%$. In contrast, for $\mathrm{G}=0.2 \mathrm{~m}$, the thermal efficiency was boosted up to $13.0 \%$. For both cases of $G$, changing $L$ had negligible effects on the trend of the data while increasing $h$ shifted the curves up for both values of G. Therefore, increasing $\mathrm{h}$ boosted the thermal efficiency.

The trends of $\eta / \eta_{\text {base }}$ versus the position of $\mathrm{OB}, \mathrm{y}$, are similar to those of $\Delta \mathrm{T}$. According to (7), the thermal efficiency change resulted from the change of both the flow rate and the temperature rise. As the change of the flow rate was minor (Fig. 6), the thermal efficiency changes mostly contributed to the change of the temperature rise. 


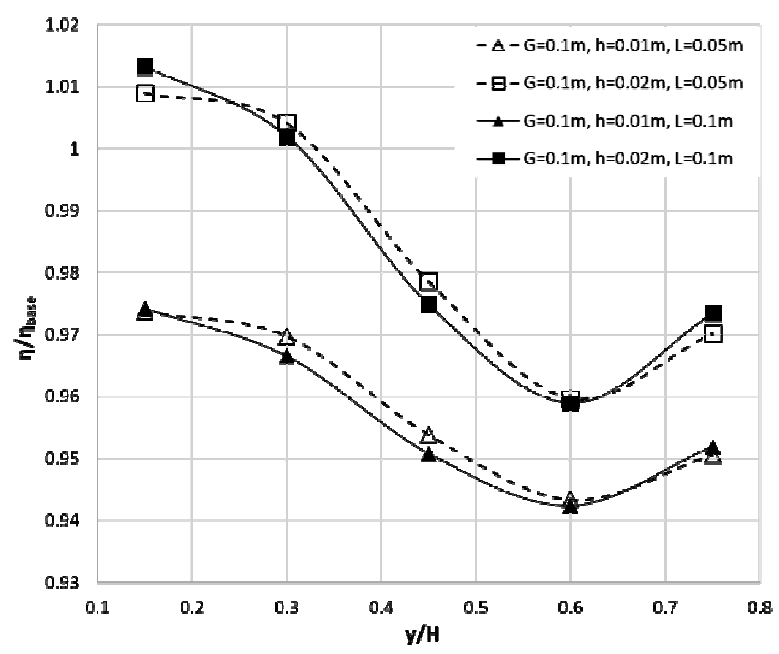

(a)

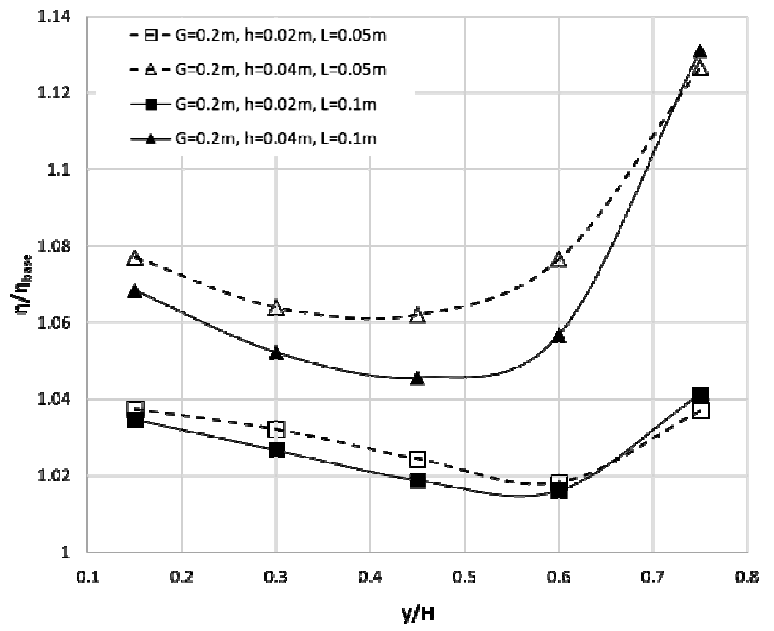

(b)

Fig. 8 Plots of the thermal efficiency ratio $\eta / \eta_{\text {base }}$ for $\mathrm{G}=0.1 \mathrm{~m}$ (a) and $\mathrm{G}=0.2 \mathrm{~m}$ (b) at different values of $\mathrm{h}, \mathrm{L}$, and $\mathrm{y}$.

\section{IV.CONCLUSION}

With the obstacle on the air channel's heated surface, the flow and temperature fields close to the object were strongly disturbed. The thermal boundary layer was enlarged around the obstacle. The enlarged region was enhanced as the obstacle approached the outlet of the air channel. This fact resulted in increasing the temperature rise, up to $13 \%$ compared to the base case.

The local Nusselt number significantly decreased before and after the obstacle where the flow and the temperature fields were strongly disturbed. Far upstream and downstream of the obstacle, the local Nusselt number was close to that of the base case. The averaged Nusselt number on the whole heated wall tended to decrease. However, the reduction was only less than $5.0 \%$ for the tested cases. Although the flow field was strongly disturbed around the obstacle, the air channel outlet's flow structure was similar to the case without an obstacle in the air channel. Change of the induced flow rate caused by the obstacle's presence was minor and less than $4.0 \%$ compared to that of the base case.

Change of the thermal efficiency due to the obstacle had similar trends to those of the temperature rise. For the cases with smaller gap, $\mathrm{G}=0.1 \mathrm{~m}$, the thermal efficiency decreased.
For the cases with the larger gap, $\mathrm{G}=0.2 \mathrm{~m}$, it increased up to $13.0 \%$.

Among the two dimensions of the obstacle, the height $h$ was seen to have more effects than the length L. Increasing h resulted in a decrease on the averaged Nusselt number and increase of the temperature rise and the thermal efficiency. The effects of changing $L$ on the above parameters were insignificant. Although some effects of the obstacle have been observed in this study, the induced flow rate, which is the main parameter for ventilation application of solar chimneys, was not enhanced. Therefore, more investigations are suggested for this objective.

\section{REFERENCES}

[1] L. Shi and M. Y. L. Chew, "A review on sustainable design of renewable energy systems", Renewable and Sustainable Energy Reviews, vol. 16(1), pp. 192-207, 2012.

[2] R. Khanal and C. Lei, "Solar chimney-A passive strategy for natural ventilation", Energy and Buildings, vol. 43(8), pp. 18111819,2011

[3] L. Shi, G. Zhang, W. Yang, D. Huang, X. Cheng, and S. Setunge, "Determining the influencing factors on the performance of solar chimney in buildings", Renewable and Sustainable Energy Reviews, vol. 88 , pp. 223-238, 2018.

[4] A. Y. K. Tan and N. H. Wong, "Natural ventilation performance of classroom with solar chimney system", Energy and Buildings, vol. 53, pp. 19-27, 2012.

[5] O. Saadatian, C. H. Lim, K. Sopian, and E. Salleh, "A state of the art review of solar walls: Concepts and applications", Journal of Building Physics, vol. 37, pp. 55-79, 2013.

[6] B. Zamora and A. S. Kaiser, "Optimum wall-to-wall spacing in solar chimney shaped channels in natural convection by numerical investigation", Applied Thermal Engineering, vol. 29(4), pp. 762$769,2009$.

[7] N. Dimassi and L. Dehmani, "Performance comparison between an improved and a classical Trombe wall: An experimental study", Journal of Building Physics, vol. 40, pp. 372-395, 2017.

[8] E. M. A. Mokheimer, M. R. Shakeel, and J. Al-Sadah, "A novel design of solar chimney for cooling load reduction and other applications in buildings", Energy and Buildings, vol. 153, pp. 219230, 2017.

[9] A. Al Touma and D. Ouahrani, "Performance assessment of evaporatively-cooled window driven by solar chimney in hot and humid climates", Solar Energy, vol. 169, pp. 187-195, 2018.

[10] A.C. Briga Sá, A. Martins, J. Boaventura-Cunha, J. Carlos Lanzinha, and A. Paiva, "An analytical approach to assess the influence of the massive wall material, thickness and ventilation system on the Trombe wall thermal performance", Journal of Building Physics, vol. 41, pp. 445-468, 2018.

[11] H. Wang and C. Lei, "Theoretical modeling of combined solar chimney and water wall for buildings", Energy and Buildings, vol. 187, pp. 186-200, 2019.

[12] S. A. M. Burek and A. Habeb, "Air flow and thermal efficiency characteristics in solar chimneys and Trombe Walls", Energy and Buildings, vol. 39(2), pp. 128-135, 2007.

[13] Y. Lei, Y. Zhang, F. Wang, and X. Wang, "Enhancement of natural ventilation of a novel roof solar chimney with perforated absorber plate for building energy conservation", Applied Thermal Engineering, vol. 107, pp. 653-661, 2016.

[14] R. Elghamry and H. Hassan, "Experimental investigation of building heating and ventilation by using Trombe wall coupled with renewable energy system under semi-arid climate conditions", Solar Energy, vol. 201, pp. 63-74, 2020.

[15] K.S. Ong, "A mathematical model of a solar chimney", Renewable Energy, vol. 28, pp. 1047 - 1060, 2003.

[16] J. Mathur, S. Mathur, and Anupma, "A novel design of solar chimney for cooling load reduction and other applications in buildings", Energy and Buildings, vol. 153, pp. 219-230, 2017

[17] I. Zavala-Guillén, J. Xamán, I. Hernández-Pérez, I. Hernández-Lopéz, M. Gijón-Rivera, and Y. Chávez, "Numerical study of the optimum width of 2a diurnal double air-channel solar chimney", Energy, vol. 147, pp. 403-417, 2018. 
[18] R. Khanal and C. Lei, "A numerical investigation of buoyancy induced turbulent air flow in an inclined passive wall solar chimney for natural ventilation," Energy and Buildings, vol. 93, pp. 217-226, 2015 .

[19] H. H. Al-Kayiem, K. V. Sreejaya, and A. O. Chikere, "Experimental and numerical analysis of the influence of inlet configuration on the performance of a roof top solar chimney," Energy and Buildings, vol. 159, pp. 89-98, 2018.

[20] M. K. Singh, S. Kumar, R. Ooka, H. B. Rijal, G. Gupta, and A. Kumar, "Status of thermal comfort in naturally ventilated classrooms during the summer season in the composite climate of India," Building and Environment, vol. 128, pp. 287-304, 2018

[21] D. R. Pangavhane, S. L. Sawhney, and P. N. Sarsavadia, "Design, development and performance testing of a new natural convection dryer", Energy, vol. 27, pp. 579-90, 2002.

[22] P. Chorin, F. Moreau, and D. Saury, "Heat transfer modification of a natural convection flow in a differentially heated cavity by means of a localized obstacle", International Journal of Thermal Sciences, vol. 151 , art. nu. 106279, 2020.
[23] G. Gan, "Simulation of buoyancy-induced flow in open cavities for natural ventilation", Energy and Buildings, vol. 38(5), pp. 410-420, 2006.

[24] Y Q. Nguyen and J. C. Wells, "Effects of wall proximity on the airflow in a vertical solar chimney for natural ventilation of dwellings", Journal of Building Physics, vol. 44(3), pp. 225 - 250, 2020.

[25] Y Q. Nguyen and J. C. Wells, "A numerical study on induced flow rate and thermal efficiency of a solar chimney with horizontal absorber surface for ventilation of buildings", Journal of Building Engineering, vol. 28, art. nu. 101050, 2020.

[26] V. Yakhot and SA. Orszag, "Renormalization group analysis of turbulence. I. Basic theory", Journal of Scientific Computing, vol. 1(1), pp. 3-51, 1986.

[27] G. Gan, "Impact of computational domain on the prediction of buoyancy-driven ventilation cooling", Building and Environment, vol. 45(5), pp. 1173-1183, 2010. 